\title{
An optical coherence tomography study of residual subfoveal fluid after successful pars plana vitrectomy in patients with diabetic tractional macular detachment
}

\author{
Mushfig I. Karimov ${ }^{1} \cdot$ Elmar M. Gasymov $^{1} \cdot$ Irada J. Aliyeva $^{1} \cdot$ Lale A. Akhundova $^{1} \cdot$ Gunay R. Rustambayova $^{1}$ • \\ Khalid D. Aliyev ${ }^{1}$
}

Received: 10 November 2017 / Revised: 20 March 2018 / Accepted: 25 March 2018 / Published online: 23 May 2018

(c) The Royal College of Ophthalmologists 2018

\begin{abstract}
Purpose To analyze the prevalence of residual subfoveal fluid (RSF) after pars plana vitrectomy in patients with proliferative diabetic retinopathy complicated by tractional detachment of the macula and the effect of RSF on the postoperative visual outcome.

Methods This study was a prospective observational case study of the optical coherence tomography (OCT) records of 23 patients (24 eyes) with macula-off diabetic tractional retinal detachment (TRD) who underwent successful 23-gauge pars plana vitrectomy between July 2012 and December 2015.

Results The prevalence of RSF on OCT examination was $100 \%$ at 1 and 2 months, $91.7 \%$ at 3 months, $70.8 \%$ at 6 months, $25.0 \%$ at 9 months and $4.2 \%$ at 12 months after surgery $(p<0.001)$. Internal drainage of subretinal fluid (SRF) during primary surgery was performed in $13(54.2 \%)$ eyes. The significant risk factor that was predictive of long-standing RSF was non-drainage of $\operatorname{SRF}(p=0.04)$.

Conclusion Persistent RSF is a common OCT finding after clinically successful vitrectomy surgery for the treatment of macula-off diabetic tractional retinal detachment. Internal drainage of SRF with active aspiration can be attempted if intraoperative breaks are found or if faster recovery is required. To date, observation seems to be the best option.
\end{abstract}

\section{Introduction}

Currently, diabetic retinopathy is one of the major causes of legal blindness among the working-age people in developed countries [1, 2]. Early panretinal photocoagulation (PRP) may prevent or delay visual loss from advanced complications of diabetic retinopathy [3-5]. However, despite timely PRP, in a substantial number of cases, diabetic retinopathy will progress to stages requiring vitrectomy. The 5-year cumulative rate of pars plana vitrectomy in ETDRS patients with timely scatter photocoagulation (PRP) was 5.3\% [6]. Non-resolving vitreous hemorrhage and tractional retinal detachment (TRD) historically have been two major indications for pars plana vitrectomy in diabetic patients [7].

Lale A. Akhundova

lala.akhundova@yahoo.com

1 Zarifa Aliyeva National Ophthalmology Centre, 32/15 Javadkhan str., Baku AZ1114, Azerbaijan
The results of surgical management of macula-off TRD depend on many factors, such as duration of macular detachment, timing of surgery, and extent of macular ischemia [8-10].

The introduction of optical coherence tomography (OCT) into clinical practice has contributed significantly to revealing subtle changes in the macular structure after vitrectomy for various retinal pathologies [11-15]. Many studies have addressed issues of persistent submacular fluid after vitrectomy for rhegmatogenous retinal detachment detectable by OCT examination [16-20]. Recently, three clinical cases of delayed, gradual recovery of central vision associated with slow resolution of the subfoveolar fluid after vitrectomy for diabetic tractional macular detachment were described [21]. We did not identify any other references to persistent subretinal fluid after vitrectomy surgery for diabetic tractional detachment with macular involvement using the PubMed database.

The purpose of this study was to analyze prevalence of residual subfoveal fluid (RSF) after pars plana vitrectomy in patients with proliferative diabetic retinopathy complicated 
by tractional detachment of the macula and the effect of RSF on postoperative visual outcomes.

\section{Materials and methods}

In this prospective observational case study, OCT records of patients with proliferative diabetic retinopathy and maculaoff TRD, who underwent pars plana vitrectomy were analyzed. The foveal detachment was confirmed by a preoperative OCT scan of the macula. The study included only the eyes that showed successful anatomical results and completed a 12-month follow-up period with OCT examinations. No eye had a history of anti-VEGF injection at least 1 year prior to surgery. Based on the medical history with/without consecutive OCT scans, we divided the macular detachment into acute ( $\leq 1$ month duration) and chronic (>1 month). OCT examinations were performed on the spectral domain Cirrus HD-OCT (Carl Zeiss Meditec, Dublin, CA, USA) over at least 6-week intervals. The following two protocols were used: the Macular cube $512 \times$ 128 with retinal thickness measurement in 9 zones and a 5line HD raster examination.

\section{The surgical technique}

A 23-gauge microinvasive vitrectomy was performed in all cases. When a combined surgery was planned, phacoemulsification of the cataract with the implantation of the IOL was conducted at the beginning of the surgery. Pars plana vitrectomy was performed using the Accurus 800CS or Constellation surgical systems (Alcon, Forth Worth, Tex., USA) and BIOM $4 \mathrm{~m}$ wide-angle posterior segment visualization system (Oculus, Germany). In most cases, preretinal membranes were removed with a vitreous cutter, and microscissors rarely used. Internal drainage of the subretinal fluid (SRF) was carried out if a preexisting or iatrogenic retinal tear was observed intraoperatively. Drainage was usually performed at the top of the detachment away from the macula and major vascular arcades using a 23 -gauge active aspiration. In the presence of epiretinal membranes with a high risk of postoperative re-proliferation, internal limiting membrane (ILM) peeling was carried out after staining with brilliant blue $\mathrm{G}$ dye (BBG) using disposable ILM forceps (Alcon, USA). For silicone oil tamponade, 1000 centistoke silicone oil was used. For gas tamponade, a non-expansile concentration of $14 \% \mathrm{C}_{3} \mathrm{~F}_{8}$ was used.

\section{Statistical analysis}

The obtained data were processed using IBM SPSS Statistics software, version 20.0 (IBM Corp., Armonk, NY,
USA). For statistical analysis, BCVA was converted from decimal values into LogMAR (logarithm of the minimum angle of resolution) values. The quantitative values are presented as the mean \pm standard deviation. The Mann-Whitney $U$-test was used to compare the time of complete resorption of the RSF among different groups. The Friedman test was used for testing the differences among the measures taken during the visits. A logistic regression analysis was performed to determine whether preoperative or intraoperative factors were significant predictors of long-standing RSF. Long-standing RSF is nonresolving RSF at $>6$ months. The adjusted odds ratios and $p$-values for the tests of significance of coefficients were obtained for each variable in the multivariate analysis.

This study was approved by the Scientific Council of the Z. Aliyeva National Ophthalmology Center. Written informed consent was obtained from all participants.

\section{Results}

Between July 2012 and December 2015, 24 eyes of 23 patients (10 males, 13 females) with proliferative diabetic retinopathy complicated by macula-off TRD underwent pars plana vitrectomy in the Department of Diabetic Eye Disease at the Zarifa Aliyeva National Ophthalmology Centre (Baku, Azerbaijan) with a mean follow-up of 16.70 \pm 4.07 months (range, 12-26 months). The mean age of the patients was $52.78 \pm 8.9$ years (range, 26-63 years). 2 patients $(8.7 \%)$ had type 1 diabetes and 21 patients $(91.3 \%)$ type 2 diabetes. The duration of diabetes was $14.77 \pm 5.1$ years (range, 4-22 years). The preoperative data and surgical details are presented in Table 1 .

Intraoperative drainage of the subretinal fluid was performed through a drainage retinotomy in 13 (54.2\%) eyes outside the major vascular arcades by active aspiration. However, despite all efforts, the subretinal fluid was difficult to completely remove due to its thick, viscous consistency.

\section{Anatomical results}

Of 13 eyes with silicone oil tamponade, the silicone oil was removed without complications in all eyes. The mean duration for silicone oil removal was $9.20 \pm 6.65$ months (range, 2-19 months).

The preoperative macular SRF height was noted as $361.56 \pm 239.27 \mu \mathrm{m}$ (range, 112-900 $\mu \mathrm{m}$ ). The central foveal thickness (CFT) before surgery was $692.89 \pm 265.18$ $\mu \mathrm{m}$ (range, 290-1200 $\mu \mathrm{m}$ ). The residual RSF was detected by OCT examination in all eyes after surgery. The height of the RSF on the first postoperative OCT scan was $234.12 \pm$ $135.33 \mu \mathrm{m}$ (range, 74-574 $\mu \mathrm{m}$ ). The RSF level diminished 
Table 1 Preoperative data and details of surgical interventions

\begin{tabular}{|c|c|c|}
\hline & & $n(\%)$ \\
\hline \multirow{2}{*}{$\begin{array}{l}\text { Duration of macular } \\
\text { detachment }\end{array}$} & $\leq 1$ month (Acute) & $11(45.8 \%)$ \\
\hline & $>1$ month (Chronic) & $13(54.2 \%)$ \\
\hline \multirow[t]{2}{*}{ Lens status } & Phakic eye & $21(87.5 \%)$ \\
\hline & Pseudophakic eye & $3(12.5 \%)$ \\
\hline \multirow{3}{*}{$\begin{array}{l}\text { Preoperative panretinal } \\
\text { photocoagulation (PRP) }\end{array}$} & None & $11(45.8 \%)$ \\
\hline & Incomplete & $9(37.5 \%)$ \\
\hline & Complete & $4(16.7 \%)$ \\
\hline \multirow[t]{3}{*}{$\begin{array}{l}\text { Preoperative posterior } \\
\text { hyaloid status }\end{array}$} & $\begin{array}{l}\text { Adherent only at } \\
\text { posterior pole }\end{array}$ & $3(12.5 \%)$ \\
\hline & $\begin{array}{l}\text { Adherent to the } \\
\text { periphery but in } \leq 2 \\
\text { quadrants }\end{array}$ & $11(45.8 \%)$ \\
\hline & $\begin{array}{l}\text { Adherent in }>2 \\
\text { quadrants }\end{array}$ & $10(41.7 \%)$ \\
\hline \multirow{2}{*}{$\begin{array}{l}\text { ERM on preoperative OCT } \\
\text { scan }\end{array}$} & Yes & $19(79.2 \%)$ \\
\hline & No & $5(20.8 \%)$ \\
\hline \multirow{2}{*}{$\begin{array}{l}\text { CME on preoperative OCT } \\
\text { scan }\end{array}$} & Yes & $12(50 \%)$ \\
\hline & No & $12(50 \%)$ \\
\hline \multirow[t]{2}{*}{$\begin{array}{l}\text { Combined surgery } \\
\text { (phacovitrectomy) }\end{array}$} & Yes & $\begin{array}{l}8(38.1 \%) \text { (of } \\
\text { phakic eyes) }\end{array}$ \\
\hline & No & $16(66.7 \%)$ \\
\hline \multirow{2}{*}{$\begin{array}{l}\text { Intraoperative drainage of } \\
\text { SRF }\end{array}$} & Yes & $13(54.2 \%)$ \\
\hline & No & $11(45.8 \%)$ \\
\hline \multirow[t]{2}{*}{ Vitreous cavity tamponade } & Silicone oil & $13(54.2 \%)$ \\
\hline & Gas & $11(45.8 \%)$ \\
\hline \multirow{2}{*}{$\begin{array}{l}\text { Internal limiting membrane } \\
\text { peeling }\end{array}$} & Yes & $16(66.7 \%)$ \\
\hline & No & $8(33.3 \%)$ \\
\hline
\end{tabular}

with time and eventually resolved in all eyes without any additional intervention (Fig. 1). The mean RSF resorption time was $7.78 \pm 3.49$ months after vitrectomy (range, 3-19 months, median 7.50 months). During the follow-up period from months 1 to 12 , the RSF decreased significantly $(p<0.001$, Friedman test) (Table 2$)$. The prevalence of RSF on OCT examination was $100 \%$ at 1 and 2 months, $91.7 \%$ at 3 months, $70.8 \%$ at 6 months, $25.0 \%$ at 9 months and $4.2 \%$ at 12 months after surgery. The rate of complete resorption of RSF differed between the various groups (Table 3).

Analysis of individual and multiple factors in logistic regression analysis revealed that significant risk factor predictive for long-standing RSF is non-drainage of SRF (B $=2.62$, odds ratio $=13.74, p=0.04$ ). Other risk factors are non-significant and not reported in this article.

\section{Functional results and their association with SRF resolution time}

The mean $\log$ MAR visual acuity improved from a preoperative value of $1.53 \pm 0.70$ to $1.00 \pm 0.63$ at 6 months and showed further improvement to $0.94 \pm 0.65$ at 1 year $(p=0.005$, Friedman test).

\section{Discussion}

Tractional macular detachment remains one of the severe complications of PDR, and, even with successful surgery, visual recovery is often slow and may even take 1 year [10, 22]. OCT imaging of the macular area can provide considerable help in explaining the mechanisms behind delayed functional recovery. Persistent «blebs», or «clefts» of SRF can be seen after macroscopically successful surgery for retinal detachment, including scleral buckling surgery [16]. The incidence of residual submacular fluid on the first postoperative OCT scan (4-6 weeks after surgery) for rhegmatogenous retinal detachment, according to various authors, varies from 15 to $90 \%$ [13, 16-18]. The origin of persistent SRF in these cases is not fully understood. It has been suggested that the fluid may be of exudative origin or represent choroidal leakage [17, 23]. However, most authors have concluded that the chronic course of detachment is a predisposing factor that leads to changes in viscosity, protein composition and cellularity of the SRF, which slows fluid absorption [16, 24]. Tee et al. [16], in comparing SRF absorption rates after RD surgery in patients with atrophic and tractional tears, discovered that chronic detachments associated with atrophic tears required a three times greater period for SRF resorption when compared with acute detachments associated with tractional tears [16].

Barzideh and Johnson [21] described the presence of subfoveolar fluid in three patients after surgery for diabetic tractional macular detachment. In all three cases, resorption of the subretinal fluid occurred gradually with complete resorption occurring within half a year, and the fluorescein angiography failed to show the presence of an exudative component. The authors also observed an association between the persistence of SRF and delayed visual recovery.

This study is the first systematic analysis of RSF resorption in the macular area based on SD-OCT examination after vitrectomy for macula-off TRD. Our findings suggest that delayed RSF resorption is a common characteristic in clinically successful vitrectomy surgery for macula-off TRD. Such a common feature of persistent RSF after TRD surgery may be associated with the chronic nature of fluid in TRD. Although we arbitrarily divided eyes into «acute» (up to one month) and «chronic» macular TRD, we were unable to identify a significant difference in the RSF resorption times between these groups. It should be mentioned that the so-called «acute» tractional detachments of the macula are, in fact, progression of the 
Fig. 1 The right eye of patient J., 55 -year-old male with chronic macular detachment and asteroid hyalosis. OCT scans

preoperatively, at 1 month,

2 months, 3 months, 4 months,

6 months, 7 months, 8 months, and 10 months after vitrectomy with silicone oil injection (removed 9 months after surgery). SRF shows gradual absorption
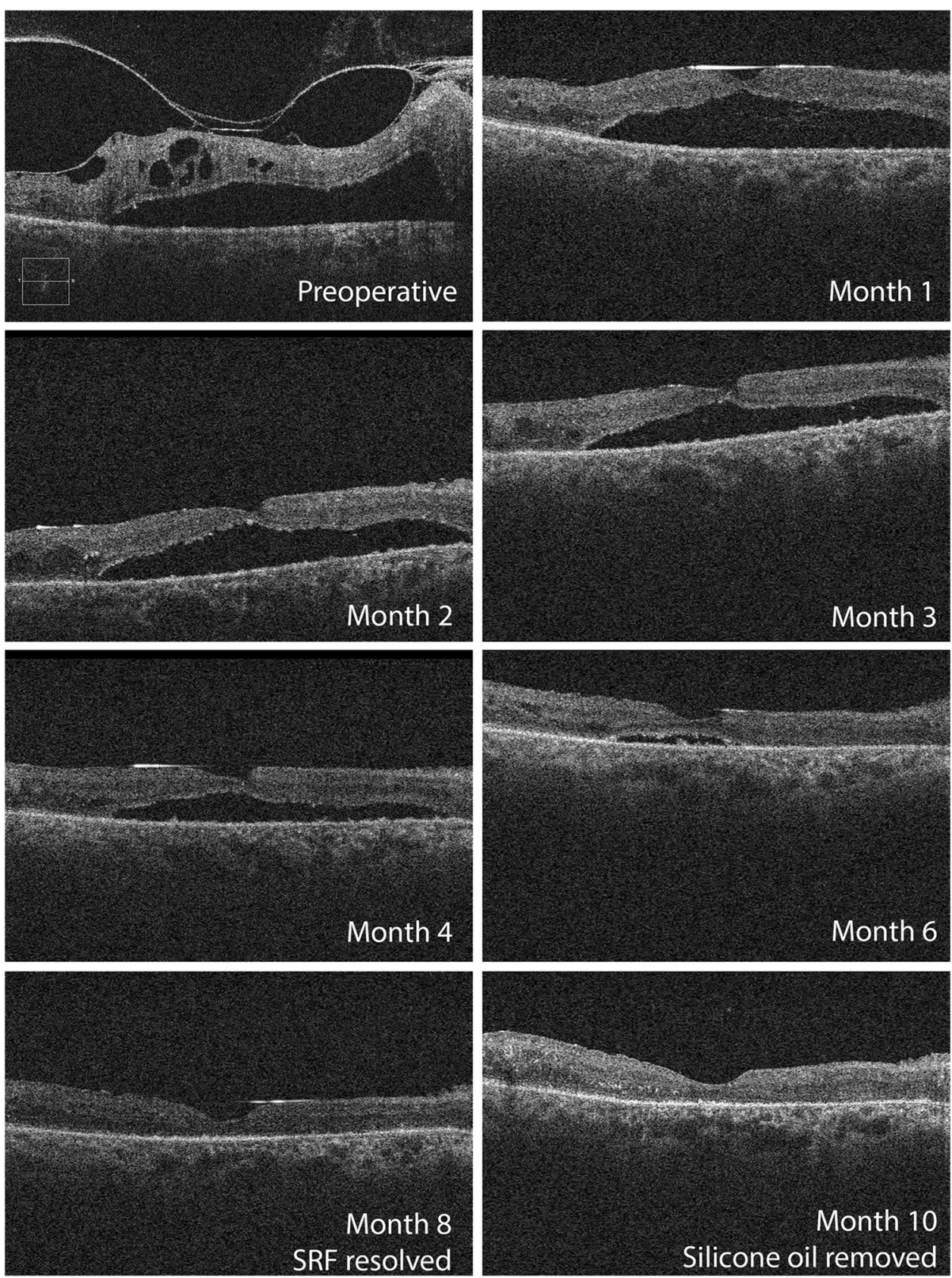

asymptomatic chronic peripheral detachment to the macular area with the emergence of acute symptoms, which, on the whole, does not change the chronic character of the SRF.

Controversial attitudes exist among authors regarding the drainage of the SRF during vitrectomy surgery. Veckeneer et al. [25], suggesting that long-standing SRF can lead to irreversible changes in the photoreceptor layer of the retina, recommended subretinal lavage during vitrectomy in chronic rhegmatogenous retinal detachments to prevent persistent SRF. In contrary, Meredith et al. [26] described the technique of membrane segmentation in patients with
TRD in PDR and indicated that there was no need to drain the SRF, since with the elimination of all epiretinal traction the retina would reattach spontaneously. A similar opinion is supported by some modern authors [27, 28]. The patients in our series underwent intraoperative drainage of the SRF with active aspiration, although the resorption time was somewhat reduced $(6.85 \pm 0.85$ and $9.09 \pm 1.06$ months, drained and non-drained cases, respectively). Here we suggest that a small number of cases in these groups did not have the power to avoid false-negative errors. In addition, we found that a significant risk factor predictive for longstanding RSF at 6 months is non-drainage of the $\operatorname{SRF}(p=$ 
Table 2 Postoperative variations in BCVA, RSF and central foveal thickness (CFT)

\begin{tabular}{lllllll}
\hline & Mo 1 & Mo 3 & Mo 6 & Mo 9 & Mo 12 & $p^{\text {a }}$ \\
\hline BCVA, LogMAR & $1.53 \pm 0.70$ & $1.18 \pm 0.77$ & $1.00 \pm 0.63$ & $1.09 \pm 0.82$ & $0.94 \pm 0.65$ & 0.005 \\
RSF thickness, $\mu \mathrm{m}$, & $210.83 \pm 144.45$ & $193.0 \pm 61.47$ & $126.67 \pm 149.46$ & $13.0 \pm 31.84$ & $11.50 \pm 28.17$ & 0.001 \\
mean \pm SD & & & & & & \\
CFT thickness, $\mu \mathrm{m}$, & $435.0 \pm 150.49$ & 412.17 & $289.17 \pm 186.13$ & 201.33 & $210.0 \pm 43.45$ & 0.008 \\
mean \pm SD & & \pm 115.05 & & \pm 69.52 & & \\
\hline
\end{tabular}

${ }^{\mathrm{a}}$ Friedman Test

Table 3 Mean RSF resorption time in different groups

\begin{tabular}{lllll}
\hline & & $\begin{array}{l}\text { Number of } \\
\text { eyes }\end{array}$ & $\begin{array}{l}\text { Months } \\
\text { Mdn (IQR) }\end{array}$ & $p^{\mathrm{a}}$ \\
\hline All eyes & & 24 & $7.5(5.0)$ & \\
Macular TRD & $\leq 1$ month & 11 & $8.5(4.0)$ & 0.652 \\
duration & $\geq 1$ month & 13 & $6.5(5.0)$ & \\
Intraoperative & Yes & 13 & $6.0(5.5)$ & 0.098 \\
drainage & No & 11 & $9.0(3.0)$ & \\
Endotamponade & Silicone oil & 13 & $7.0(5.0)$ & 0.014 \\
& Gas & 11 & $10.0(5.0)$ & \\
\hline
\end{tabular}

${ }^{a}$ Mann-Whitney $U$-test

0.040). It should also be emphasized that we did not plan intraoperative drainage in our patients in advance, and this was done only if intraoperative breaks (preexisting or iatrogenic) were found. As visible from the figures above, the prolonged SRF resorption was held despite intraoperative drainage, as drainage was not complete due to the thick, viscous nature of SRF. We did not perform subretinal lavage of fluid with BSS, as recommended by Veckeneer [25], as we did not consider it safe for diabetic retina with abnormal retinal outer layers.

We used silicone oil in 13 cases (54.2\%) and gas in 11 cases $(45.8 \%)$ as an endotamponade at the end of surgery. Long-lasting tamponading agents, such as silicone oil or perfluoropropane, were used when intraoperative breaks were found and internal drainage of SRF was performed. An interesting finding in our study was faster reabsorption of SRF in eyes that underwent silicone oil tamponade, that can be probably related to the fact that the silicone oil was a preferred choice of endotamponade in cases with intraoperative breaks and internal drainage.

Our study has several limitations, including the absence of randomization and small sample size, not sufficiently powered to detect significant relationship with some tests. Further studies in larger patient samples are needed to validate our findings and to study the implications in the pathogenesis of RSF and treatment of patients with chronic TRD.

In summary, we have shown that persistent RSF is detectable by OCT after successful surgery for TRD due to proliferative diabetic retinopathy. Internal drainage of SRF with active aspiration, although it hastens fluid resorption only partially, can be attempted when intraoperative breaks are found. In all cases the fluid reabsorbed spontaneously, and this was associated with improving visual acuity.

\section{Summary}

\section{What was known before}

- Persistent subretinal fluid as a frequent OCT finding after vitreoretinal surgery for rhegmatogenous retinal detachment.

- Slow visual rehabilitation after vitrectomy for PDR. Few cases of slow subretinal fluid absorption after diabetic vitrectomy.

\section{What this study adds}

- Persistent residual subfoveal fluid is a common OCT finding after vitrectomy in macula-off diabetic tractional retinal detachment.

- Internal drainage of subretinal fluid can be attempted if intraoperative breaks are found or if faster recovery is required.

\section{Compliance with ethical standards}

Conflict of interest The authors declare that they have no conflict of interest.

\section{References}

1. Mohamed Q, Gillies MC, Wong TY. Management of diabetic retinopathy: a systematic review. JAMA. 2007;298:902-16.

2. Cheung N, Mitchell P, Wong TY. Diabetic retinopathy. Lancet. 2010;376:124-36.

3. Diabetic Retinopathy Study Research Group: Photocoagulation treatment of proliferative diabetic retinopathy: Relationship of adverse treatment effects to retinopathy severity. The Diabetic Retinopathy Study report No. 5. Dev Ophthalmol. 1981;2:248-61.

4. Diabetic Retinopathy Study Research Group: Photocoagulation treatment of proliferative diabetic retinopathy:. The second report of The Diabetic Retinopathy Study findings. Ophthalmology. 1978;85:82-106.

5. Vine AK. The efficacy of additional argon laser photocoagulation for persistent, severe proliferative diabetic retinopathy. Ophthalmology. 1985;92:1532-7. 
6. Flynn HW Jr, Chew EY, Simons BD, Barton FB, Remaley NA., Ferris FL. Pars plana vitrectomy in the Early Treatment Diabetic Retinopathy Study. ETDRS report number 17. The Early Treatment Diabetic Retinopathy Study Research Group. Ophthalmology. 1992;99:1351-7.

7. The Diabetic Retinopathy Vitrectomy Study Research Group. Early vitrectomy for severe vitreous hemorrhage in diabetic retinopathy. Two-year results of a randomized trial. Diabetic Retinopathy Vitrectomy Study reports 2. Arch Ophthalmol. 1985;103:1644-52.

8. Thompson JT, de Bustros S, Michels RG, Rice TA. Results and prognostic factors in vitrectomy for diabetic traction retinal detachment of the macula. Arch Ophthalmol. 1987;105:497-502.

9. Abunajma MA, Al-Dhibi H, Abboud EB, et al. The outcomes and prognostic factors of vitrectomy in chronic diabetic traction macular detachment. Clin Ophthalmol. 2016;10:1653-61.

10. Ostri C, Lux A, Lund-Andersen H, la Cour M. Long-term results, prognostic factors and cataract surgery after diabetic vitrectomy: a 10-year follow-up study. Acta Ophthalmol. 2014;92:571-6.

11. Schocket LS, Witkin AJ, Fujimoto JG, et al. Ultrahigh-resolution optical coherence tomography in patients with decreased visual acuity after retinal detachment repair. Ophthalmology. 2006;113:666-72.

12. Baba T, Hirose A, Muka M, Mochizuki M. Tomographic image and visual recovery of acute macula-off rhegmatogenous retinal detachment. Graefes Arch Clin Exp Ophthalmol. 2004;242:576-81.

13. Wolfensberger T, Gonvers M. Optical coherence tomography in the evaluation of incomplete visual recovery after macula-off retinal detachments. Graefes Arch Clin Exp Ophthalmol. 2002;240:85-89.

14. Sanghi G, Padhi TR, Warkad VU, Vazirani J, Gupta V, Dogra MR, Gupta A, Das T. Optical coherence tomography findings and retinal changes after vitrectomy for optic disc pit maculopathy. Indian J Ophthalmol. 2014;62:287-90.

15. Dooley I, Laviers H, Papavasileiou E, Mckechnie C, Zambarakji H. Spectral domain ocular coherence tomography findings preand post vitrectomy with fibrovascular membrane delamination for proliferative diabetic retinopathy. Eye. 2016;30:34-9.

16. Tee JJ, Veckeneer M, Laidlaw DA. Persistent subfoveolar fluid following retinal detachment surgery: an SD-OCT guided study on the incidence, aetiological associations, and natural history. Eye. 2016;30:481-7.
17. Benson SE, Schlottmann PG, Bunce C, Xing W, Charteris DG. Optical coherence tomography analysis of the macula after vitrectomy surgery for retinal detachment. Ophthalmology. 2006;113:1179-83.

18. Benson SE, Schlottmann PG, Bunce C, Xing W, Charteris DG. Optical coherence tomography analysis of the macula after scleral buckle surgery for retinal detachment. Ophthalmology. 2007;114:108-12.

19. Ricker LJ, Noordzij LJ, Goezinne F, Cals DW, Berendschot TT, Liem AT, et al. Persistent subfoveal fluid and increased preoperative foveal thickness impair visual outcome after macula-off retinal detachment repair. Retina. 2011;31:1505-12.

20. Hagimura N, Iida T, Suto $K$, et al. Persistent foveal retinal detachment after successful rhegmatogenous retinal detachment surgery. Am J Ophthalmol. 2002;133:516-20.

21. Barzideh N, Johnson M. Subfoveal fluid resolves slowly after pars plana vitrectomy for tractional retinal detachment secondary to proliferative diabetic retinopathy. Retina. 2007;27:740-3.

22. Nakazawa M, Kimizuka Y, Watabe T, Kato K, et al. Visual outcome after vitrectomy for diabetic retinopathy. A five-year follow-up. Acta Ophthalmol. 1993;71:219-23.

23. Kang SW, Kim JH, Shin WJ, Kim JI. Subretinal fluid bleb after successful scleral buckling and cryotherapy for retinal detachment. Am J Ophthalmol. 2008;146:205-10.

24. Veckeneer M, Derycke L, Lindstedt EW, van Meurs J, Cornelissen M, Bracke M, et al. Persistent subretinal fluid after surgery for rhegmatogenous retinal detachment: hypothesis and review. Graefes Arch Clin Exp Ophthalmol. 2012;250:795-802.

25. Veckeneer M, van Aken E, Wong D, Reyniers R, van Meurs J. Subretinal lavage to prevent persistent subretinal fluid after rhegma- togenous retinal detachment surgery: a study of feasibility and safety. J Clin Exp Ophthalmol. 2011;2:154.

26. Meredith TA, Kaplan HJ, Aaberg TM. Pars plana vitrectomy techniques for relief of epiretinal traction by membrane segmentation. Am J Ophthalmol. 1980;89:408-13.

27. Gupta B, Sivaprasad S, Wong R, et al. Visual and anatomical outcomes following vitrectomy for complications of diabetic retinopathy: the DRIVE UK study. Eye. 2012;26:510-6.

28. Qamar RM, Saleem MI, Saleem MF. The outcomes of pars plana vitrectomy without endotamponade for tractional retinal detachment secondary to proliferative diabetic retinopathy. Int J Ophthalmol. 2013;18:671-4. 